\title{
Exploring Intersections of Employment and Ethnicity Amongst British Pakistani Young Men.
}

\author{
by Hasmita Ramji \\ City University
}

Sociological Research Online, Volume 10, Issue 4,

< http://unw. socresonline.org.uk/10/4/ramji.htm/>

doi:10.5153/sro. 1144

Received: 30 Nov 2004 Accepted: 4 Oct 2005 Published: 31 Dec 2005

\begin{abstract}
This article draws upon research conducted amongst young British Pakistani men in Lancashire to explore how different boundaries of British Pakistani identity are being constructed. It focuses on the significance of employment within Pakistani men's inter and intra-ethnic peer group relations and the ways in which the social dynamics that underlie those relations provide the context for understanding the particular nature and form that ethnicity takes. It does this through the narratives of professional and non-professional men. The article has two aims, firstly it seeks to contribute to the literature on understanding ethnic identity by looking at boundaries as they manifest themselves and suggesting one way in which ethnicity can be understood within a specific social context. Secondly, in so doing it hopes to extend research focus on British Pakistanis away from conventional agendas.
\end{abstract}

\section{Keywords: Employment, Ethnicity, Class, British Pakistani Men}

\section{Introduction}

1.1 This paper presents extracts from discussions with young British Pakistani men in Lancashire to explore how class positions and ethnicity ${ }^{[1]}$ intersect in the construction of differing British Pakistani identity boundaries. This paper focuses on the boundaries apparent in the interview discussion advanced by research respondents located in professional and non-professional occupations ${ }^{[2]}$. Analysis of the characteristics which respondents described as differentiating 'Us' from 'Them' suggested that the boundaries drawn by the two groups of men were expressed through an evaluation of the type of Pakistani ethnicity most useful and valuable as capital in the social field they occupied as a result of their of class status. The article seeks to contribute to the literature on understanding ethnic identity by looking at boundaries as they manifest themselves and suggesting one way in which ethnicity can be understood within a specific social context. In doing so it hopes to extend the research focus on Pakistani ethnicity beyond established agendas. The article uses Bourdieu's concepts of capital and field to explore the respondents' interviews.

\section{The Research}

2.1 This paper draws on interviews carried out amongst men who were living in Blackburn, a town on the traditional Lancashire textile belt. Blackburn is one of five local authorities that make up East Lancashire and represents one of the biggest regeneration challenges in Britain. The area is a target of the government's Pathfinder schemes. The statistics in East Lancashire are worrying; home to 500, 000 people, more than a third of teenagers leave school with no qualifications. Wage levels in what was the cradle of the industrial revolution are significantly below the national and regional averages. There is no economic growth

[3]. Polarised communities split on ethnic lines are easy prey to the British National Party, which counts the area as one of its few electoral successes. The Pakistani Muslim community constitutes nearly $40 \%$ percent of the population in Blackburn, forming one of the largest non-white communities in East Lancashire (Lancashire County Council, 2003).

2.2 The research reported on here forms a small part of a three year project entitled 'Employment and Social Change Amongst British Asians' which began in 2003. This research seeks to aid the understanding of Britain's South Asian communities, the variations within it and the nature and diversity of inequality it faces by exploring how labour market positions influence identity formations amongst the different elements 
making up the grouping. The recognition of internal (community, religious, class, spatial and gender) differences amongst the 'Asian' grouping has grown in importance, as it becomes increasingly obvious that settlers of differing backgrounds are following varied and often sharply contrasting social trajectories (Modood et al 1997). The data presented was obtained by carrying out in-depth interviews with a sample of twenty young (18- 30 year old) British Muslim men of Pakistani descent. Using the Census (2001) categories this first set of interviewees were selected to give an occupational sample (10 respondents were working professionals and 10 were non-professionals employed in unskilled or semi skilled employment) which reflected differing age, ethnicity, religion and gender categories. As no random sampling frame exists for British South Asians the research relied on a snowball sample obtained through contacts made in the preliminary fieldwork stage of the project. ${ }^{[4]}$

2.3 Before turning to the present study, it is useful to begin by outlining the popular stereotypes apparent in the current hypervisibility of Pakistani Muslims in Britain in order to demonstrate why a greater understanding is needed. The paper will then discuss how Bourdieu's concepts of capital and field can aid analysis of relational difference. The remaining part of the paper will discuss the research respondents' interviews to highlight how strategies for negotiating British Pakistani identities operate with different conceptions of Pakistani ethnicity as capital.

\section{Anger Young Men?}

3.1 There is an increasing correlation being made in both popular and wider perceptions between young Muslim men's ethnicity and underclass status (Alexander, 2000) ${ }^{[5]}$. They continue to be stereotypically associated with a range of social problems. Pakistani male youth has been identified as consistently underperforming in both the education sector and the labour market (Modood et al 1997; Brown, 2000; Dale, 2002; PIU, 2002). Unemployment levels are up to five times those of white Britons. They are most likely to get the worst jobs, the lowest wage and face widespread discrimination. Even after allowances for education and residential area, Pakistani Muslims are three times more likely to be jobless than Indian Hindus are (PIU, 2002). A new sense of danger also accompanies contemporary perceptions of Pakistani men. In their analysis of 1995 public disturbances in Bradford, for instance Burlet and Reid (1998) argue the incidents mark a change in Pakistani male behaviour in the public sphere from orderly protest to violence and disorder. The space for alternative images is 'surveyed, patrolled, legislated and censored' (Alexander, 2000: xiii). Their 'unacceptable' behaviour is consistently read as an inevitable part of their cultural background and consequent culture clash with the mainstream 'white' British society (Taylor, 1976) ${ }^{[6]}$. Culture is increasingly seen as the problem especially if you are Muslim. The sustained focus on Asian cultural ethnicity as the definer of self identity has the effect of obscuring the structural positioning of Asian communities (Eade, 1996). This not only perpetuates an analysis of their inequality as different to the majority's experience of inequality but leads to the perception that their ethnicity necessitates underclass status without exploring why underclass status seems to necessitate ethnicity. Recent writers on British Asians have argued that 'by framing questions of culture as dichotomous and oppositional, traditional or Western, the clash of culture thesis fails to come to grips with the complex realities of South Asian [. . .] everyday lives (Ramji, 2003: 229). Macey (1999: 845), for instance suggests that Burlet and Reid's (1998) analysis prioritises cultural differences over gender, age and class location. The continued focus on deprived sections of the Pakistani community means there is a danger of this being regarded as the only experience, restricting however unintentionally a more wide-ranging understanding of class and ethnicity. It is more useful to take account of the heterogeneous experiences of the British Pakistani community, for instance in specific relation to this paper the range of employment positions occupied, to dispel popular and misleading correlations between ethnicity and social inequality.

\section{Bourdieu: Fields and Capitals}

4.1 Recent literature has emphasised the complex intersections between ethnicity, gender and class and the contradictory ways in which they are frequently expressed (Hall 1990). Bourdieu's work on social fields and capital aids this relational understanding of 'difference'. He conceptualised competing yet related struggles over a range of scarce goods and resources (Bourdieu 1977, 1990). These goods and resources, are conceived of as four types of capital: economic capital, class roughly in the Marxist sense; cultural capital, legitimate knowledge and behaviour; social capital, the prestige and influence gained and enjoyed through networks with significant others and symbolic capital, which in essence is constituted through the legitimate acknowledgement and recognition by others that someone has acquired one or more of the previous forms of capital (Bourdieu, 1987: 3-4). To understand the specific relationships that develop as individuals and groups compete over particular forms of capital, Bourdieu introduced the concept of 'field'. A field is primarily defined by the particular forms of capital perceived as present and valuable. As Bourdieu (1993: 73 with emphasis in the original) explains:

The structure of the field is a state of the power relations among agents or institutions 
engaged in the struggle, or, to put it another way, a state of the distribution of the specific capital which has been accumulated in the course of previous struggles and which orients subsequent strategies.

4.2 There are many different forms of capital whose significance can never be guaranteed. Rather, particular forms of capital will be distinctly/highly valued within certain fields but will be devalued and/or used to signify subordinate status in other fields. Moreover, because of the different forms of capital that exist, we can conceive of a wide range of distinct fields; each organised around particular forms of capital. It is precisely this diversity in the forms of capital and their associated fields that aids our understanding of the multiple and contradictory nature of any individual's identity as they move from one field of relations to another (Connolly, 2000). The young men interviewed differed in their relation to the social field of employment because of their differing occupations and this led to a differing evaluation of the capital present and desired. The qualities of their shared Pakistani ethnicity were perceived differently and a struggle at an intra-group group level was occurring to establish possession of the most sought after Pakistani ethnicity. Individual strategies in any social field are concerned with the preservation or improvement of their positions with respect to the defining capital of the field. The identification of certain social codes as being important to success resonates with Bourdieu's theory that certain attributes or habituses operate as symbolic and cultural capital, which qualify people to rise in given social fields. The boundaries of any particular field in terms of the nature of the capital present and who and what are drawn into its domain are not fixed but are strongly contested by those within the field (Wacquant 1989).

4.3 Establishing the Pakistani ethnicity that each group saw as most useful to their positioning as the Paksitani 'capital' meant drawing boundaries to safeguard its position. Jenkins (1996) cites how normative mechanisms, such as the shared understandings of contextual codes and social practices, act to highlight boundaries between 'Us and 'Them'. A distinction was developing between the professional and nonprofessionals conceptualisation of what was Pakistani ethnicity and consequently what codes of behaviour this entailed. Barth has noted 'the cultural differences of primary significance for ethnicity are those that people use to mark distinction, the boundary' (1994: 12). Boundaries are the point where group similarities end and differences begin. Cohen (1985:12) describes how symbolic boundaries presuppose inclusion and exclusion and are constructed through social practices, attitudes or values that are affirmed and re-affirmed through interaction. The process of belonging therefore requires 'boundary work', and the active maintenance and negotiation with others (whether imagined or in practice) of guiding frameworks for inclusion. The contrasting occupational positions of the cohorts was important because the 'others' (peers, work colleagues etc.) which were used as reference points to draw boundaries were different. As Young notes 'what makes the group a group is the relation in which it stands to others' (Young 1997: 389). According to Lamont (1992: 11), boundary work is a process of personal investment in identity because it is: ' . . an intrinsic part of the process of constituting the self; they [boundaries] emerge when we try to define who we are: we constantly draw inferences concerning our similarities to, and differences from, others, indirectly producing typification systems.' Recent discussions on difference have maintained this stress on relationality and on the organisation of diversity. The boundaries of belonging and non-belonging were drawn differently by the Pakistani men researched. Each defined Pakistani ethnicity differently to fit into their employment status and general social positioning. They sought to establish their placement within this desired Pakistani ethnicity boundary and place 'Others' with differing employment status outside this boundary and with consequent access to a lower Pakistani ethnic capital.

\section{Employment Discussions}

5.1 Bourdieu's concepts then provide an analytical basis from which we can begin to understand why fields of relations become differentiated along ethnic lines and, with reference to the specific form of capital present, to explain the particular nature and form that ethnic distinction adopts in this context. I have organised the interview material below around two key themes that emerged, firstly the perception of the link between ethnicity and employment and secondly the specific attributes of Pakistani ethnicity.

5.2 Azam's (aged 20) was one of first interviews I conducted and was indicative of the type of young men who were seen to occupy the 'underclass'. Though Azam was working many of his contemporaries were not. He had a temporary job in a warehouse and had experienced frequent periods of unemployment. He was the only member of his family employed at the time of the interview. He had left school with no GCSEs. After starting a NVQ course in the September after leaving school he had stopped attending college after it became 'too heav' and 'pointless'. He did not regret his decision.

\section{$\mathrm{H}$ : Didn't you want to stay on at college?}

A: There was no point, man. If I thought it would do any good don't you think I would have?

I'm doing as well I would have done. 
A: If I'd stayed on I don't think I would I been anywhere higher or better.

The working class sample evaluated themselves as having little economic capital. Another respondent Mohamed commented:

M: What would I have done with the qualifications anyway? Where would I get a job? Those types of jobs aren't given to us.

$\mathrm{H}$ : Can you tell me what types of jobs you mean?

M: Proper jobs, posh jobs you know doctors, lawyers, chemists . . .

5.3 The 'working class' young men I interviewed were quite sure that employment spaces were demarcated along ethnic lines. There were some jobs that just weren't available to Pakistanis. Moreover the belief that 'higher your get the less Pakistanis you see' confirmed their understanding that 'posh jobs', or professional occupations had as much if not more discrimination as any other type of employment. This evaluation of the social field of employment made them see their own working class status as the norm for Pakistanis. The overwhelming sentiment amongst this cohort was that Pakistani Muslim background confined them to working class occupations. Class was intimately connected to the way that ethnicity was perceived. Their interviews were imbued with a sense of powerlessness 'resignation of the inevitable' (Bourdieu, 1984: 372) characteristic of working class habitus. It was difficult for Pakistani young men to occupy this 'professional' space and 'coming good' through conventional routes of education and employment did not entail access to this space. Their type of ethnicity was not compatible with or welcome in these spaces. Middle class identities it seems are synonymous with whiteness.

They're never going to let us in, never going to accept us. . . all the good jobs are kept for white people.

So what if you are a doctor, you will always be a Pakistani doctor.

5.4 This seems consistent with findings on the raced and classed nature of privileged spaces, or what Puwar refers to as the existence of a 'somatic norm' (Puwar, 2001: 652). The somatic norm is one of the primary ways in which latent racism manifests itself in institutions. Whereas the professional cohort's location within privileged spaces made them susceptible to the assimilative pressure to conform and adapt their ethnicity to the norm the non-professional respondents were outside the space and showed a greater awareness of a normative pressure. Not only were they outside the space but they did not need to imbibe the legitimate code of behaviour for their career progression. Acquiring these subtle codes is part of the process of 'becoming' or performing middle class etiquette, which is a 'simultaneous performance of a particular variant of whiteness and a disavowal of blackness' (Puwar, 2001: 663). This perception of the relationship between their ethnicity and employment possibilities was compounded by the type of work scenarios they were familiar with. In short their everyday working lives did little to challenge their perceptions.

5.5 There was a clear separation amongst this cohort between employers and colleagues on the basis of ethnicity. The men worked in a range of jobs where the 'bosses' were depicted as 'white and stuck up' and their work colleagues were differentiated on ethnic lines. Their 'friends at work' all tended to be of the same ethnic origin and this effected the type of Pakistani ethnicity this cohort utilised. Whilst it is not possible to discuss it here there exists an established literature on differential association, which asserts that individuals tend to associate with those they share most characteristics with, in short 'like attracts like' (Bourdieu, 1990;Bottero and Irwin, 2003). The particular population makeup of Blackburn sustained this closed interaction.

5.6 Imtiaz (aged 24) left school with a couple of GCSEs and 'floated around' until he found a job in a factory packaging food. When asked how he found the work he replied stoically:

I: The factory was born for me and I was born for the factory . . . it's a sealed fate.

$\mathrm{H}$ : What do you think of the work?

I: It's just work . . it's always going to be the same. I don't get anything out of it . . .

$\mathrm{H}$; Do you have many friends at work?

I: Yeah, but most of them aren't just people I met at work I mean I knew them from round here or school . . . anyway most of them are Pakistani so it's [. . .], like I know them straight away 
anyway.

\section{H: How do you mean?}

I: We have a common understanding and [this means] at work I have people that understand me, all of us lot stick together. No one hassles us that way, and well we can look after ourselves. We don't need any outsiders to help us out.

5.7 The cohort were constructing, maintaining and regulating an ethnicity which would withstand the negative aspects of the social field of employment they were experiencing. Strength was sought in collective numbers. The most common way they did this was through seeing social mobility not as individualised but as a process determined by society, and its prejudices. These working class men conflated their ethnic and class positions and perceived them as ordinary. Mohamed, in his discussion about work and Pakistani ethnicity touched upon a common sentiment when he summarily claimed:

I am just your common, average Paki'

5.8 They cited their ordinariness to argue that their social positioning was less a product of individual responsibility and more of social effect. Their ordinary position was intimately linked to their ethnicity and so 'out of their hands'.

Being born Pakistani means that some things are always going to be out of your reach, its better that you understand that early on, otherwise you'll learn later [. . .] the hard way. Its better for you to concentrate on making the most of what you do have and not worry about missing out. Make those on the outside feel as if they are missing out.

5.9 There seemed to be parallels between seeking affirmation of 'typical', 'common' and 'average' 'Paki' status and strategies of claiming ordinariness discussed in other literature (Savage et al 2001, Skeggs 1997). Invoking ordinariness has popularly been interpreted as method of avoiding class by underplaying distinction and thus resisting (negative) labelling by dominant groups. The non professional men however, also seemed to differ from the strategy of ordinariness discussed in other studies in key ways. Whereas research conducted amongst white populations has found respondents wanting to see themselves as 'outside' class to undermine its salience the men I spoke to used ordinariness as a structurally located strategy to make sense of their positioning, a way to explain the opportunities available and denied to them. A new generation of class theorists have argue that hierarchical positions of class continue to constrain aspirations and tastes, social networks and resources but on a individual rather then collective level (Devine and Savage, 2000; Bradley 1996; Reay 1998; Bottero and Irwin 2003). It is worth pointing out that the majority of this research draws on white experiences and it is suggested in this paper that an analysis of Pakistanis as a racialised minority suggests the presence of individualized and collective notions of class amongst Pakistani men in the social field of employment.

5.10 The cohort displayed inverted pride in their 'underclass' positions and this was linked to perceiving their experience as the 'normal', 'average' and 'ordinary' experience. The boundary of being normal and one of 'Us' and different and one of 'Them' was drawn here on the basis of their everyday experiences and what they saw around them. Their economic positions prevented their access to other 'posh' or middle class cultural and social capital so they increasingly saw their ethnicity as a way of acquiring status and recognition. They devised a strategy to avoid low cultural and social capital by anchoring high cultural and social capital in a distinguished Pakistani ethnicity and separating it from prestigious economic positioning.

5.11 This Pakistani ethnicity had to be imbued with positive qualities to counteract exclusion elsewhere but also had to have a boundary which served to make it exclusive. This exclusivity was apparent in claims about the inaccessibility of Pakistani culture to outsiders. Mohamed's particular position was exclusively his, and only people in a similar class and ethnic position could understand it. The exclusivity around being 'Us' was made apparent by Azam in a discussion about the job market in Blackburn and the recent regeneration efforts being made by the Council he said:

These people they think they know us, they think they can help us. But they don't know us so they can't help us. They don't live next to us they don't go to the same school as us and they don't work with us.

5.12 One of the ways this boundary was drawn was through the widespread positive appropriation of derogatory 'paki' label. It has become a term of reference used by young working class British Pakistani men to refer to their peers. Although used in white society as a derogatory term for all Asians, the term seems to have been procured exclusively by the Pakistani Muslim community. It usage appeared markedly similar to the collective terms used to refer to Black Americans in the United States. Whilst acceptable for 
an insider, it is still highly offensive if used by someone outside of the Pakistani community. Bourdieu argues that language acts as an important marker of distinction between 'Them' and 'Us' (1992: 45). State language is the 'legitimate' norm against which other linguistic practices are measured. The legitimate language is the preserve of the upper classes but is also acquired by those who do not have this class exposure through the educational system. Therefore capital acquired in school is transferred to work. These men did not have access to this and established there own linguistic codes which as the extracts presented here demonstrate contained a high level of slang as well as Punjabi.

5.13 Another way the working class cohort sought to establish high social and cultural capital within this boundary was depicting their social positioning as the old, established and traditional Pakistani identity. Their position seemed to encapsulate the essence of being a true Pakistani and this was connected to being working class. Social mobility seemed connected to selling out and ultimately corruption of ethnic and religious ideals.

I know that I am never going to sell out because I am never to leave here. I will always be true to what I am. These people they think they will be more acceptable to ghoras (whites) if they live somewhere else, say the right things and wear the right clothes. Stop making smelly Paki food and wearing Paki clothes. But ultimately you will always be a Paki, ain't a [ . . ] thing you can do about that.

5.14 'They' are working to be something different because their shared, traditional identity was not good enough. Their underprivileged space it appears is exclusively to be occupied by true Pakistanis. This means seeing upward mobility as an undesirable break with tradition.

I don't understand these Pakis who [. . . ] make out they're better or different [. . . ] they've moved no where apart from away from their roots [. . . ] not living in an Asian area is [not] going to make them less Asian . . . they're just fools.

5.15 For the working class men religion provided the clearest expression of group identification and acted to cement other salient boundaries. An excessive concern with fitting in, and social status away from this frame of reference was for 'them' not 'us'. They cared about more important things.

You don't have to be successful or rich to belong to Islam

5.16 Religion in turn seemed intimately connected with ethnicity. As indicated in other studies the way religion was embraced and incorporated was selective and often contradictory (Macey 1999: 852). They were aware that their religious identity was attracting increasing attention.

Everyone is scared of Islam [. . .] the government, the police everyone. They are more sacred of what Islam can make us do then anything else.

5.17 Whilst not the focus of this paper the importance this group of men attached to religion must be noted. Jacobson (1997) notes the trend to distinguish ethnicity and religion amongst young British Pakistanis. The former is associated with the traditional cultures of their parents and rejected, and the latter embraced as an 'alternative' self definition freeing the individual to embrace a global, culture-free identity. Azam like many of the young men I interviewed like him saw British Muslim identity as powerful source of identity.

Being a Muslim is stronger then being an individual. It makes everything like work and family problems seem small [. . . ] it puts everything else into perspective. When you belong to a something that is spread across the world, has millions of followers, who all do what you do, pray when you do, fast when you do, it makes you feel strong inside.

5.18 Their 'proper' understanding of Islam was used to mark the exclusive boundaries of their ethnicity. Azam attended the mosque regularly and tried to observe the five times of prayer. His parents he describes as

not religious really more superstitious. You know, like they do things just because they have always done them that way. It has very little to do with Islam . . . its more about Pakistani culture. They are more worried about what the Pakistani community around them will think about what they are doing [... ] then really bothering to analyse why they're doing the things they do'

5.19 Azam's parents like many of the Pakistanis settled in the UK originate directly from the Mirpur. ${ }^{[7]}$ district and have a rural background. Azam believed that his parent's generation did not understand Islam 'properly'. They certainly had not observed it 'properly'. This would seem to contradiction the suggestion by 
Anwar (1986), Rex and Josephides (1987), Shaw (2000) and Modood (1997) that the attitude of Muslim youth are closer to their parents. However any suggestion of an inter-generational clash of culture is problematised by the discrepancy between the attitudes and behaviour expressed and the high levels of contradiction in young men's use of Islam. This is supported by other studies which have found that young men have mobilised a particular Islamic code as a power resource. (Macey, 1999: 857). Attitude to religion is complicated by the perception of many other factors including racially based exclusion. For this cohort the overt display of Islam (e.g. wearing traditional dress at Friday prayers) was a successful display of a working class man 'knowing his roots', not 'trying to get ahead of himself', 'knowing [his] limits', of 'keeping himself pure'. Formulating boundaries within the community (generational and/or class divisions) between who really understood Islam and those who didn't and placing themselves with the former grouping was part of a strategy of claiming this important aspect of ethnic capital for themselves. Given their low levels of economic capital it was not surprising that this cohort drew boundaries and frameworks for evaluating status and possession of Pakistani ethnic capital around religion and maintenance of cultural traditions. This meant they could have a higher cultural and social capital then their economic positions allowed for.

\section{Middle Class Spaces}

6.1 The professional men interviewed had high levels of economic capital and thus had access to middle class cultural, social and symbolic capitals. What seemed to be of prime concern to them with was possession of a Pakistani ethnicity which complimented this access. They were trying to renegotiate a different way of understanding and being Pakistani because they did not relate to being Pakistani in the same way as their non-professional counterparts. For their Pakistani background to have relevancy and meaning to their lives it would have to be imbued with different capitals. This echoes previous research which found that the up and coming Indian professionals were renegotiating cultural identities not abandoning them (Ramji, 2003).

6.2 This cohort did not see Pakistani ethnicity as linked to low occupation status. Moving away from collective belonging they saw Pakistani identity as a product of individual enterprise not structural placement. Conventional class boundaries were being eroded by people 'educating and working themselves up'. British Pakistanis were not excluded from this but could be active participants in this erosive process. Education and employment achievements were an important part of claiming responsibility for class positioning. Javed ( 25 years old), a junior doctor argued

If you study and make something of yourself then you can get away from the things that hold you back. You can [improve] the position you find yourself in.

6.3 Individual class positions enabled an assessment of individual effort, that is whether they'd utilised the opportunities made available to them. As Tariq comments:

From my experience, people usually end up in jobs they deserve. If you can't be bothered to study or you let other people's prejudice hold you back well then the only person who loses out is you. If [Pakistanis] can overcome the stereotypes and get on regardless not only do they get something for themselves but they also change attitudes by proving them wrong.

6.4 This groups' Pakistani ethnicity was to be renegotiated on an individual level.

It's all about using the avenues available to you to get away from being stuck in a position. If you get an education then no one is going to take that away from you [. . . ] If I'm made redundant I know that I stand a better chance of getting another job because I trained as an accountant. My parents were always vulnerable in a way this generation of Pakistanis don't have to be - the question is do they want to work.

This way of rationalising choices in education and careers to minimise falling foul of the employment market was clearly evident. But it was also felt that professional spaces offered greater opportunities to challenge popular stereotypes.

A lot of people have assumptions about what my attitudes are going to be, but when they get to know me they realise that actually I am quite normal [. . .] you know not some religious fundamentalist, or sexist oppressor or whatever [ . . ] I shop, eat out and enjoy the same things as everyone else.

6.5 Acceptance into middle class spaces entailed 'clarifying Pakistani culture'. This meant confronting and disproving stereotypes. Traditional formats of Pakistani ethnicity were stale and out of touch with their lifestyles, they were making a move from the old to the new. Whereas the non-professionals saw themselves as occupying and marking the boundaries of traditional 'true Pakistani ethnicity' the professionals saw themselves as creating a new space which was relevant to them and their social 
positioning, that is a Pakistani ethnicity which was a true reflection of their generation. Moreover this didn't rely on belonging to a collective but was a personal project.

Being Pakistani for me is about getting away from what the white community assumes about you, getting away from what the Pakistani community tells you to assume about yourself, and about thinking how you want to be.

6.6Whereas, for the non-professional men their parents' working class identity was the historical referent for their collective Pakistani identity, this cohort of men declared their parents as migrants outside of conventional class analysis.

I'm not sure you can really talk about my parents as having a class identity because they were immigrants and didn't really get a chance to achieve much.

Their middle class identity did not extend backwards to their parental generation and it was seen as their responsibility to carve out this space for Pakistanis. Again the effort to play the individual off against the structural limitations is evident here.

6.7 Whereas the working class men thought about their future as being located in the Blackburn job market these men were already thinking of how securing employment elsewhere would enable them to relocate. All of these respondents had moved away from Blackburn either to go to University or for career training. They all had aspirations to move away. Most sought after were 'cosmopolitan' spaces which one respondent Shazad, an IT consultant described as a place:

Where brown faces do not stand out or are too many.

These spaces usually meant cities.

I don't want to live around the corner from the mosque. I don't want to only see brown faces. I want to live in a city, somewhere where I have a clean slate. Where no one knows who I am and where I can do what I like.

6.8 Irfan was a young doctor who had just brought his flat in a fashionable, affluent area of Manchester. When asked if he thought moving away would affect his relationship with the Pakistani community, he replied

I don't need to be around lots of [other] Pakistanis to know who I am.

Geographical mobility was starting to emerge as an important strand to renegotiating Pakistani ethnicity. It may provide as some suggest, knowledge and experience of 'other' cultural orientations and consequently a capacity for critical abstraction (Southerton, 2002: 187, Lamont, 1992). Holt's (1997) analysis suggests that the distinction between local and expansive frames of reference is central for understanding how cultural resources are mechanisms for framing interpretations of social standing. It would seem that access to professional economic capital was opening up venues to social and cultural capital, which were alternatives to the traditional Pakistani ethnic capital that the working class cohort were distinguishing.

6.9 As well as viewing the relationship between class and ethnicity differently these men's middle class occupations influenced the type of Pakistani ethnicity they saw as capital. According to Bourdieu (1984) distaste or/and distinction from the 'Other' are, central to middle class identities. As Reay notes to 'claim middle class status is not the same as inhabiting a middle class identity' (1998: 260). In order to support their legitimacy in middle class spaces these men needed to have different capital attached to Pakistani identities and this meant a change that others would recognise. Puwar (2001: 653) argues that privileged occupational spaces are imbued with a white, male middle class somatic norm and this sets the context for ethnic adaptation. Obtaining economic, social, cultural and symbolical capital in these spaces meant the possession of a Pakistani ethnicity that was not too distinct from the established norm. A Pakistani ethnicity was thus sought where the boundaries fell not on distinct traditions and religious teaching but which demonstrated cultural compatibility with British middle class cultural spaces. For this cohort this was a broadening not narrowing down of Pakistani ethnicity. The subtle codes of behaviour demanded by their work spaces were observed in socialisation practices. The cultural capital of having a diverse group of friends was seen as more desirable for Pakistanis instead of 'sticking with their own'. Most of these professionals had accumulated a racially diverse circle of friends, usually through study and work.

I like to go out with lots of different types of people. At work I have a Irish friend and a German friend as well as all my English friends [. . . I I find it socialising with different people interesting because I learn more about other cultures. 
All my family is Pakistani so why would I need or want to have all my friends as Pakistani as well?

I don't think I am only a Pakistani [. . .] I want to be many things. Why they [other Pakistanis] fix on to this identity as if it was the only thing that mattered I don't know [they're] not appreciating that it has been made important [. . .] it doesn't necessarily have to be important'.

6.10 There is an element here of conforming to the assimilative pressure that exists in privileged spaces which means the professional cohort is taking on the dominant norms, even if these are not neutral (Puwar 2001: 662). In trying to obtain the 'self-certainty' of middle class habitus (Bourdieu, 1984: 66) this cohort were concerned with gaining access to white middle class spaces and distinction from the 'Pakistani' ethnicity the working class men were so keen to cultivate. This entailed some collusion and co-operation in maintaining types of 'lower' Pakistani capital. They worked with the stereotypes of the religious fanatic and backward Pakistani but used them to measure their difference against. It was the type of Pakistani to be distinguished from. They placed little or no emphasis on the religious attributes that Pakistani ethnicity held for the working class cohort.

You don't have to be religious to be a Pakistani, or even a practising Muslim.

6.11 Pakistani culture for the middle class respondents was rich and misunderstood. They had more respect for the cultural norms and values inherited from their parents than obscure advice from the Iman. Many of these men rarely attended mosque, unless it was for a specific and important celebration, for example Eid. The mosque of their parents still held their allegiance.

People who confuse religion with culture and ethnic identity make life difficult for all of us.

6.12 There was been a strong feeling that they were comfortable in their British Pakistani identity and thus were selective in the pan-Islam one. They saw a pan-Islamic identity as highly political and having little relevance to their lives. It was dangerously high profile and associated with a backward move for the Pakistani community. Pan Islamic allegiance threatened to marginalize them further in the British context and this was not desired. They needed to accumulate the right kind of social capital and had to be careful with whom they associated.

I don't have any time for [. . .] Islamists. These people who hold on to archaic religious practices because they can't be bothered or are too scared to think for themselves. Being a Muslim for a lot of these people is showing that you belief rather then having conviction in those beliefs. One set of ideas is not going to delivery the answer to all your woes - only you can do that.

They were sceptical of the motives for obvious or public demonstrations of faith. Pakistani ethnicity didn't necessarily belong in the public sphere but was perceived as a private identity.

Holding on to the old means you are scared of the present and future.

6.13 The Pakistani professional identities were still very much middle class identities in progress. They were just getting used to being professionals and becoming mobile through work and so their boundary emphasis fell on their obvious economic differences with others. The working class men were more established and focused their attention on the religious and cultural characteristics they shared with their friends and neighbours above socio-economic evaluations. By contrast, the professional newcomers relied more heavily on categories drawn from socio-economic frameworks and generic class based characteristics when identifying with their professional colleagues.

I think the job someone does give you more of an indication about whether you are going to get on with them then their ethnicity.

6.14 Perhaps racialised existence means that gaining access to mainstream British life has become associated with up-ward mobility and this in turn is associated with respite from racial exclusion. Contrary to Savage et al who claim that 'class pollutes this idea of individuality, since it challenges people's autonomy by seeing them as the product of their social background' $(2001 ; 886)$. It seems that professional class positions for Pakistani men actually offered greater autonomy. They might still be conceived as 'reflexive class identifiers' (Savage et al, 2001: 886). That is, possessing the cultural capital to 'play around effectively with ideas of class', and having the confidence to select or reject identity labels. One perhaps cannot disguise visible difference (skin colour) in the way that one may 'perform' a different class identity. Thus power to redefine an identity may be channelled to that element most malleable to change and with the greatest chance of finding a successful acceptance. Their strategy to present and achieve a negotiated 
Pakistani ethnicity was intimately connected to their concern to gain acceptance into middle class spaces. However, the argument that class identities are more permeable then racial ones for minorities in Britain is limited by the presence of the somatic norm (Puwar, 2001). The social spaces in which new class identities are performed are not neutral.

\section{Conclusion}

7.1 This article has attempted to show how ethnicity and employment intersect in the contemporary boundaries of British Pakistani identity. The type of Pakistani ethnic capital needed depended on the type of employment that is, class position engaged in. Bourdieu's (1984) idea of class being constituted by different types of capital gives us insight into the strategies employed by the two groups of men interviewed. Whilst it is not argued here that there is a set way in which class, ethnicity and gender interact this paper is arguing that focus on a particular instance of their articulation helps to work towards a better understanding of their relation to each other. Rather then presenting a conclusive account, what is offered here is an understanding of the contexts within which these young men struggle and negotiate their social position and identities. The paper engages with questions concerning similarities and differences between and within ethnic groups and how boundaries are regulated and crossed (Barth, 1969). It also allows an exploration of the circumstances in which ethnic boundaries become more, or less, permeable and the effect of this on individuals' prioritization of particular elements of their identities. The findings in the paper provide a degree of support for Savage et al (2001), Reay (1998) and Skeggs (1997) in highlighting the continuing importance of class in identity formation whilst also concurring with work that has pointed to the relative and varied salience of class to racialised groups (Anthias, 2001).

\section{Notes}

1 Denotes a sense of 'kinship, group solidarity and common culture' (Hutchinson and Smith, 1996:3). It is accepted that gender affects the experience of ethnicity. As such the Pakistani ethnicity discussed by the male respondents in this paper may not resonate with the experiences of British Pakistani women.

${ }^{2}$ As Devine (1998) notes employment relations have been key to a number of influential models of class stratification. Such models tend to conceptualise class in minimalist economic terms rather then as collectivities of people who share identities and practices. In this paper professional and non-professional employment is used as a guide to differing class cultures and to significantly different attitudes to class mobility. However, the paper's utilization of Bourdieu's (1984) theory of social capital prevents the narrow analysis that minimalist models are frequently accused of adhering to (see Devine's critique of Goldthorpe, 1998).

3 'Hi-tech jobs targeted as blackspot is reborn' The Observer 27 June 2004.

${ }^{4}$ Although there is not the space to discuss it fuller here my own presence as a young British Asian female of Indian descent made the interview process one of simultaneous inclusion and exclusion. I could relate to the group on a general community and generational level but gender, occupation, religion and ethnicity differentiated us.

${ }^{5}$ Social scientists have become increasingly aware of the significance of Islam in a globalised, postmodern world (Modood 1992; Sahgal and Yuval-Davis 1992; Kepel 1994; Lewis and Schnapper 1994).

${ }^{6}$ The clash of culture thesis holds that the British born and raised generation of 'Asians' are caught between two incompatible cultures: their home culture and the culture of mainstream society in which they live. As this generation exposes itself to higher levels of education and employment they will move to the more dominant cultural model. Succinctly the cohort should be exhibiting signs of disenchantment with their own cultural heritage and attraction to British mainstream culture.

${ }^{7}$ Mirpur is a region of Kashmiri Pakistan where many British Pakistanis trace their roots via their parents.

\section{References}

ALEXANDER, C. (2000) The Asian Gang, Oxford: Berg.

ANTHIAS, F (2001) 'The material and the symbolic in theorising social stratification: issues of gender, ethnicity and class' British Journal of Sociology, Vol 52: No 3: 367-390.

ANWAR, M (1986) Young Muslims in a Multi cultural Society.Leicester: Islamic Foundation. 
BARTH, F (ed.) (1969) Ethnic Groups and Boundaries, Oslo: University Press.

BARTH, $F$ (1994) 'Enduring and emerging issues in the analysis of ethnicity', in H. Vermeulen and C. Grovers (eds.) The Anthropology of Ethnicity: Beyond Ethnic Groups and Boundaries, The Hague: Het Spinhuis.

BOURDIEU, P (1977) Outline of a Theory of Practice.Cambridge: Cambridge University Press.

BOURDIEU, P (1984) Distinction: A Social Critique of the Judgment of Taste, London: Routledge.

BOURDIEU, P (1987) 'What makes a social class? On the Theoretical and Practical Existence of Groups'. Berkley Journal of Sociology 32: 1-18.

BOURDIEU, P (1990) The Logic of Practice, Cambridge: Polity Press.

BOURDIEU, P (1993) Sociology in Question, London: Sage.

BRADLEY, H. (1996) Fractured Identities, Cambridge: Polity.

BROWN, M (2000) 'Religion and Economic Activity in the South Asian Population', Ethnic and Racial Studies, Vol 23, No. 6: 1045

BOTTERO, W and S. Irwin (2003) 'Locating difference: class, 'race' and gender, and the shaping of social inequalities' The Sociological Review

BURLET, S and Reid, H (1998) 'A gendered uprising: political representation and minority ethnic communities' Ethnic and Racial Studies, Vol. 21, No. 2:

COHEN, A (1985) The Symbolic Construction of Community.London: Routledge.

CONNOLLY, P (2000) 'Racism and Young Girls' Peer-group relations: The experience of South Asian girls' Sociology Vol 34 (3): 499-519.

DALE, A., N. Shaheen, V. Kalra and E. Fieldhouse (2002) 'Routes into education and employment for young Pakistani and Bangladeshi women in the UK' Ethnic and Racial Studies, Vol 25 (6): 942-968.

DEVINE, F and M. Savage (2000) 'Conclusion: Renewing Class Analysis', in R. Crompton and F. Devine, M. Savage and J. Scott (eds.) Renewing Class Analysis, Oxford: Blackwell.

DEVINE, F (1998) 'Class Analysis and the Stability of Class Relations' Sociology Vol. 32 No. 1: 23-42.

EADE, J (ed.) (1996) Living the Global City: Globalisation as Local Process, London: Routledge.

HALL, S (1990) 'Cultural Identity and Diaspora', in J. Rutherford (ed.) Identity: Community, Culture, Difference, London: Lawrence and Wishart.

HOLT, D (1997) 'Distinction in America? Recovering Bourdieu's Theory of Taste from it's critics' Poetics 25: 93-120.

HUTCHINSON, J and A.D. Smith (eds.) 1996) Ethnicity, Oxford University Press: Oxford.

JACOBSON, J (1997) 'Religion and ethnicity: dual and alternative sources of identity among young British Pakistanis', Ethnic and Racial Studies, 20 (2): 238-56.

JENKINS, R (1996) Social Identity, London: Routledge.

KEPEL, F (1994) The Revenge of GOD: The Resurgence of Islam, Christianity and Judaism in the Modern World, London: Polity Press.

LAMONT, M (1992) Money, Moral and Manners: The Culture of the French and American Upper-Middle Class, London: University of Chicago Press

LANCASHIRE COUNTY COUNCIL (2003) East Lancashire Demographic Profile: Information Unit.

LEWIS, B. and Schnapper, D . (eds.) (1994) Muslims in Europe,London: Pinter Publishers.

MACEY, M (1999) 'Class, Gender and Religious influences on changing patterns of Pakistani Muslim male violence in Bradford' Ethnic and Racial Studies Vol 22 No 5: 845-866. 
MODOOD, T (1992) 'British Asian Muslims and the Rushdie affair' in J. Donald and A. Rattansi (eds.), 'Race', Culture and Difference, London: Sage.

MODOOD, T., Berthoud, R., Lakey, J. Nazroo, J., Smith, P,. Virdee, S. Beishon, S, (1997). Ethnic Minorities in Britain, London: Policy Studies Institute.

PERFORMANCE AND INNOVATION UNIT (2002). Ethnic Minorities and Labour Markets: An Interim Analysis. Cabinet Office.

PUWAR, N (2001) 'The Racialised Somatic Norm and the Senior Civil Service' Sociology,Vol. 35, No. 3: 651-670.

RAMJI, H (2003) 'Engendering Diasporic Identities' in N. Puwar and P. Raghuram (eds.) South Asian Women in the Diaspora, Oxford: Berg.

REAY, D (1998) Rethinking Social Class: Qualitative Perspectives on Class and Gender' Sociology Vol 32 No. 2: $259-279$.

REX, J and Josephides, S. (1987) 'Asian and Greek Cypriot Associations and Identity', in Rex, J, D. Joly and C. Wilpert (eds.) Immigrant Associations in Europe, Aldershot: Gower.

SAHGAL, G. and Yuval-Davis, N (eds.) 1992 Refusing Holy Orders: Women and Fundamentalism in Britain, London: Verso.

SAVAGE, M, G. Bagnall and B. Longhurst (2001) 'Ordinary, Ambivalent and Defensive: Class Identities in the Northwest of England' Sociology Vol 35 (4) : 875-892.

SHAW, A (2000) Kinship and Continuity: Pakistani Families in Britain,London: Routledge $2^{\text {nd }}$ edition.

SKEGGS, B (1997) Formations of Class and Gender,London: Sage.

SOUTHERTON, D (2002) 'Boundaries of 'Us' and 'Them': Class, Mobility and identification in a New Town' Sociology 36 (1): 171-193.

WACQUANT, L (1989) ‘Towards a Reflexive Sociology: A Workshop with Pierre Bourdieu'. Sociological Theory 7: 26-63.

YOUNG, I.M.(1997) 'Difference as a resource for democratic communication' in Bohman, J and Regh, W (eds.) Deliberative Democracy, Cambridge: MIT Press. 